\title{
LUT
}

University

In (Big) Data we trust: Value creation in knowledge organizations Introduction to the special issue

De Mauro Andrea, Greco Marco, Grimaldi Michele, Ritala Paavo

This is a Final draft

version of a publication

published by Elsevier

in Information Processing and Management

DOI: $10.1016 / j . i p m .2018 .02 .002$

Copyright of the original publication: () 2018 Elsevier Ltd.

Please cite the publication as follows:

De Mauro A., Greco M., Grimaldi M., Ritala P. (2018). In (Big) Data we trust: Value creation in knowledge organizations - Introduction to the special issue. Information Processing and Management, Vol. 54, Issue 5. Pp. 755-757. DOI: 10.1016/j.ipm.2018.02.002 


\section{In (Big) Data we trust: Value Creation in Knowledge Organizations. Introduction to the special issue}

\section{Introduction}

Big Data is defined as "information assets characterized by such a high volume, velocity, and variety to require specific technology and analytical methods for its transformation into value" (De Mauro, Greco and Grimaldi, 2016). Due to increasing level of digitalization of businesses, and technological developments in various fields, Big Data is now widely available for companies across industries. Therefore, companies of all shapes and sizes are being forced to reconsider the role of data and analytical capabilities in their decision making, innovation management, market research, and operations management, to name a few fields (Davenport and Patil, 2012; McAfee and Brynjolfsson, 2012; Fosso Wamba et al., 2015).

Dealing with Big Data is no longer an option, but often a necessary task in the contemporary competition. Indeed, companies that have been more intentional in the use of Big Data, have shown to be more productive than their industry peers (Bughin, 2016). However, as a radical technological development, the rise of Big Data has brought along major challenges to companies. The rapid development of Big Data Analytics is often not accompanied by a controlled evolution of business processes and organizational structures. This organizational immaturity towards Big Data prevents from leveraging the full potential of its advances (Pearson and Wegener, 2013). In other words, Big Data and related technology are making society change at a speed that companies struggle to follow, and there is still lack of clarity on the complex set of drivers and inhibitors of effective value creation through Big Data (Davenport, 2014).

In this special issue, we were looking for better grasp to the aforementioned practical as well as academic gaps in our current understanding. In particular, we were looking for contributions to understand the multiple ways Big Data can impact the way business is done, and how value is created and captured. As a result, we received dozens of interesting papers touching upon the topic of Big Data from various viewpoints. The set of five accepted papers includes those that have direct implications of how Big Data helps in creating and capturing value in organizations. The papers in this issue provide both technical perspectives to how Big Data is actually utilized in organizational processes and decision making, as well as papers that touch upon broader issues such as the role of 
Big Data in marketing, customer relationship management, as well as the required skills and competencies of Big Data professionals in companies.

Overall, we see the papers in this special issue providing a useful contribution to the emerging organizational perspective to Big Data research. While a technical understanding of Big Data is elaborated widely, we are still just starting to understand how organizational aspects such as customer relationships, marketing, human resource management, as well as strategizing, are evolving as a result of Big Data. The papers in this special issue provide input to these issues and also highlight the need for further research in the area. The following sections of this editorial discuss shortly the contributions of individual papers in this special issue, after which we conclude with a future research agenda for an organizational approach of Big Data research.

\section{Description of the manuscripts}

Big Data often contributes to value creation in organizations through advanced analytics approaches. Two manuscripts included in this Special Issue explicitly focus on Big Data Analytics (BDA). Kaur Saggi and Jain's (2018) performed an extensive analysis of the literature on BDA, identifying a core base of 70 studies. Starting from them, the authors describe the fundamental characteristics of BDA, including its six main components (data generation, data acquisition, data storage, advanced data analytics, data visualization, and decision-making for value-creation), its typical tools, techniques and technologies, and its main domains of application. Verma et al. (2018) explored the relationship between BDA characteristics and the perceptions of key subjects regarding them, leveraging the Technology Acceptance Model. The authors interviewed 156 individuals experienced in data management and advanced analytics systems, measuring, among the others, the BDA systems perceived usefulness, ease of use, expected benefits, quality, as well as the users' intention to use BDA systems. The study clarifies the relationships between such constructs, emphasizing how certain characteristics of BDA systems are critical to improve the attitude of decision makers regarding their adoption and their actual usefulness.

In response to the growing interest towards $\mathrm{BDA}$, an increasing demand for Big Data professionals is emerging. De Mauro et al. (2018) provided a data-based description of job roles and skills that companies need in order to make use of Big Data. Information of the study was extracted out of online job posts data by means of web-scraping techniques and a set of text mining and classification algorithms were then applied. A systematized nomenclature and characterization of job roles and skills was built up to be used by business managers to structure their recruitment programs and functional career paths and also by universities for the sake of shaping their curricula and degree 
programs. Results give particularly useful insights for organizations and managers and offer guidance to educational institutions aiming to focus their efforts on developing the skills that are needed in the future.

Other papers in the special issue explore more specific topics that link organizational value creation to Big Data. Zerbino et al. (2018) review the broad literature related to the role of Big Data in Customer Relationship Management (CRM). In particular, the authors classify the literature in relation to the critical success factors and divide the literature accordingly. The categories include a) Strategic planning of CRM, b) Infrastructure for IT in CRM, c) Insight and data management in CRM, d) CRM project, and e) CRM and organizational impact. The study of Del Vecchio et al. (2018) focuses on a very contemporary phenomenon - that of Social Big Data. Social Big Data refers to both company and user data that is generated via social media and is characterized by different formats and contents. This paper examines "smart tourism destinations" in Apulia (Southern Italian region), showing how Social Big Data can be used for creating value in such context via improved decisionmaking, marketing strategies, interaction with stakeholders, as well as new business models.

\section{Future research directions}

Contributions captured within this special issue have shed light over the critical challenge of identifying and systematizing the multifaceted organizational aspects of Big Data exploitation in companies. Obviously, we found no single approach of parsing all the numerous ways Big Data is impacting how today's business is done, and how value is created and captured from it. However, the findings described in these papers collectively inspire further research along with various promising lines:

- It is still widely unclear how firms can get organized to effectively integrate quantitative and qualitative approaches for transforming information into competitive advantage. In fact, as noticed by multiple observers and reiterated within this special issue, both Small and Big Data have the right to co-exist in decision making. However, there is still an opportunity to investigate how organizational structure and business processes can evolve to enable a smooth integration of traditional qualitative methods and arising numeric techniques.

- Big Data has already found applications within the large majority of industries, and a plethora of broadly assorted business cases is available within business and academic literature, including the papers in this special issue. Nevertheless, there is still room for comparative analyses of the actual financial impact of Big Data initiatives in order to monetize and individually consider the relevant success factors, risks, and inhibitors. Although existing studies already claim that leveraging Big Data can bring positive returns, more work is 
required to assess which of the many alternatives paths of Big Data implementation are the most profitable. Such results will provide business managers with actionable tools for strategy setting and priority choices.

- Another promising item within the future research agenda on Big Data is related to Human Resources Development. Indeed, companies and universities share the common challenge of defining meaningful Big Data-related professional careers and educating individuals accordingly. As the half-life of analytical competencies and skills dramatically decreases, nurturing and retaining talent in the fast-moving Big Data arena requires a thorough understanding of possible mechanisms for sustainable knowledge management.

From the quantity and the quality of the submitted papers, we gladly observe as guest editors of this special issue that the academic community is actively engaged in the whole spectrum of Big Data and committed to advance the scientific understanding of associated organizational challenges and business opportunities. We wish to thank all the authors for their highly-valuable contributions and the referees who have critically evaluated the papers with rigor and dedication, making this issue possible. We would also like to express our deepest gratitude to prof. Jim Jansen, Editor in Chief of Information Processing \& Management, for his support and for giving us the opportunity to organize this special issue devoted to Big Data, which we hope readers will ultimately enjoy reading.

\section{References}

Bughin, J. (2016) 'Big data, Big bang?', Journal of Big Data. Journal of Big Data, 3(1), p. 2. doi: 10.1186/s40537015-0014-3.

Davenport, T. H. (2014) Big Data at Work: Dispelling the Myths, Uncovering the Opportunities. Harvard Business Review Press.

Davenport, T. H. and Patil, D. J. (2012) 'Data Scientist: The Sexiest Job Of the 21st Century', Harvard Business Review, 90(10), pp. 70-76.

Fosso Wamba, S., Akter, S., Edwards, A., Chopin, G. and Gnanzou, D. (2015) 'How "big data” can make big impact: Findings from a systematic review and a longitudinal case study', International Journal of Production Economics, 165, pp. 234-246. doi: 10.1016/j.ijpe.2014.12.031.

Kaur Saggi, M. and Jain, S. (2018) 'A Survey Towards an Integration of Big Data Analytics to Big Insights for Value-Creation', Information Processing \& Management.

De Mauro, A., Greco, M. and Grimaldi, M. (2016) 'A formal definition of Big Data based on its essential 
features', Library Review, 65(3), pp. 122-135. doi: 10.1108/LR-06-2015-0061.

De Mauro, A., Greco, M., Grimaldi, M. and Ritala, P. (2018) 'Human resources for Big Data professions: A systematic classification of job roles and required skill sets', Information Processing \& Management. doi: 10.1016/j.ipm.2017.05.004.

McAfee, A. and Brynjolfsson, E. (2012) 'Big data: the management revolution', Harvard business review, 90(10), pp. 61-67. doi: 10.1007/s12599-013-0249-5.

Pearson, T. and Wegener, R. (2013) Big Data: The organizational challenge. Available at: http://www.bain.com/publications/articles/big_data_the_organizational_challenge.aspx (Accessed: 20 November 2017).

Del Vecchio, P., Mele, G., Ndou, V. and Secundo, G. (2018) 'Creating value from Social Big Data: Implications for Smart Tourism Destinations', Information Processing \& Management. doi: 10.1016/j.ipm.2017.10.006.

Verma, S. and Sekhar Bhattacharyya, Som Kumar, S. (2018) 'An extension of the Technology Acceptance Model in the Big Data Analytics System Implementation Environment', Information Processing \& Management.

Zerbino, P., Aloini, D., Dulmin, R. and Mininno, V. (2018) 'Big Data-enabled Customer Relationship Management: A holistic approach', Information Processing \& Management. doi: 10.1016/j.ipm.2017.10.005.

Andrea De Mauro Department of Enterprise Engineering, University of Rome Tor Vergata, Italy Marco Greco* Department of Civil and Mechanical Engineering, University of Cassino and the Southern Lazio, Italy Michele Grimaldi Department of Civil and Mechanical Engineering, University of Cassino and the Southern Lazio, Italy Paavo Ritala School of Business and Management, Lappeenranta University of Technology (LUT), Finland m.grimaldi@unicas.it (M. Grimaldi), paavo.ritala@lut.fi (P. Ritala) 